\title{
THE FORMATION OF DRAINAGE WIND ON A SNOW-DOME*
}

\author{
By J. A. Businger and K. Ramana Rao $\dagger$ \\ (Department of Atmospheric Sciences, University of Washington, Seattle, Washington, \\ U.S.A.)
}

\begin{abstract}
Direct measurements of the horizontal divergence of the air flow close to the snow surface have been made. The mean vertical wind component has been derived from these observations. The temperature profile has been analyzed near the center of the snow-dome and a method to determine the sensible heat flux independent from the energy budget has been developed.
\end{abstract}

RÉsumé. Sur la formation de vent de drainage sur une coupole de neige. Des mesures directes de la divergence horizontale de l'écoulement de l'air près de la surface de la neige ont été éxécutées. La composante verticale moyenne du vent a été déduite de ces observations. La profil de température a été analysé près du centre de la coupole de neige et l'on a développé une méthode pour déterminer le flux calorifique sensible indépendament du bilan énergétique.

Zusammenfassung. Die Entstehung des Kaltluft-Abflusses auf einem Schneedom. Dicht über der Schneeoberfläche wurde die horizontale Divergenz der Luftströmung unmittelbar gemessen. Aus diesen Beobachtungen wurde die mittlere Vertikalkomponente des Windes hergeleitet. Das Temperaturprofil wurde nahe am Zentrum des Schneedoms untersucht; eine Methode zur Bestimmung des Flusses der fühlbaren Wärme unabhängig von der Energie-Bilanz wurde entwickelt.

\section{INTRODUGTION}

The Blue Glacier is located in the center of the Olympic National Park on the north-east slope of the Mount Olympus massif. In the upper regions of the glacier we find a snow-dome with remarkably regular features. The topography of this snow-dome and the location of the Blue Glacier field station are indicated in Figure $\mathrm{I}$.

The purpose of the study reported in this paper was to obtain a better understanding of the characteristics of the initial stage of air drainage, using relatively simple portable instrumentation. Under calm and clear weather conditions, the air in contact with snow cools and sinks resulting in a specific air drainage pattern. A special effort was made to measure the horizontal divergence of the air flow and to relate this to the observed temperature profile on the snow-dome. The sensible heat flux to the snow surface may be obtained from the temperature profile combined with the divergence of the horizontal wind.

\section{Divergence Measurements}

Two techniques were used to compute the divergence of the flow close to the surface on the top of the snow-dome. In the first, winds were recorded by six Casella anemometers, each mounted on a wooden mast at a height of $5^{\circ} \mathrm{cm}$. and arranged at positions I, 2, 3, 4, 5, and 6 on the circumference of the outer circle as shown by Figure 1 . Wind directions were recorded by automatic wind vanes at three of the anemometers and at the other three it was observed by noting the direction of incense smoke.

In the second technique, three anemometers were arranged in positions $\mathrm{I}, 3$, and 5 on the outer circle of radius $125 \mathrm{~m}$. and the other three at 7,8 , and 9 on the inner circle of radius $62.5 \mathrm{~m}$.

Temperatures were measured at the center of the circle by a small thermistor thermometer.

\section{Vertical Velocities}

The horizontal divergence over the center of the snow-dome is a direct consequence of the

* Department of Atmospheric Sciences, University of Washington, Contribution No. Iog.

$\uparrow$ Now at Department of Meteorology, University of Wisconsin, Madison, Wisconsin, U.S.A. 


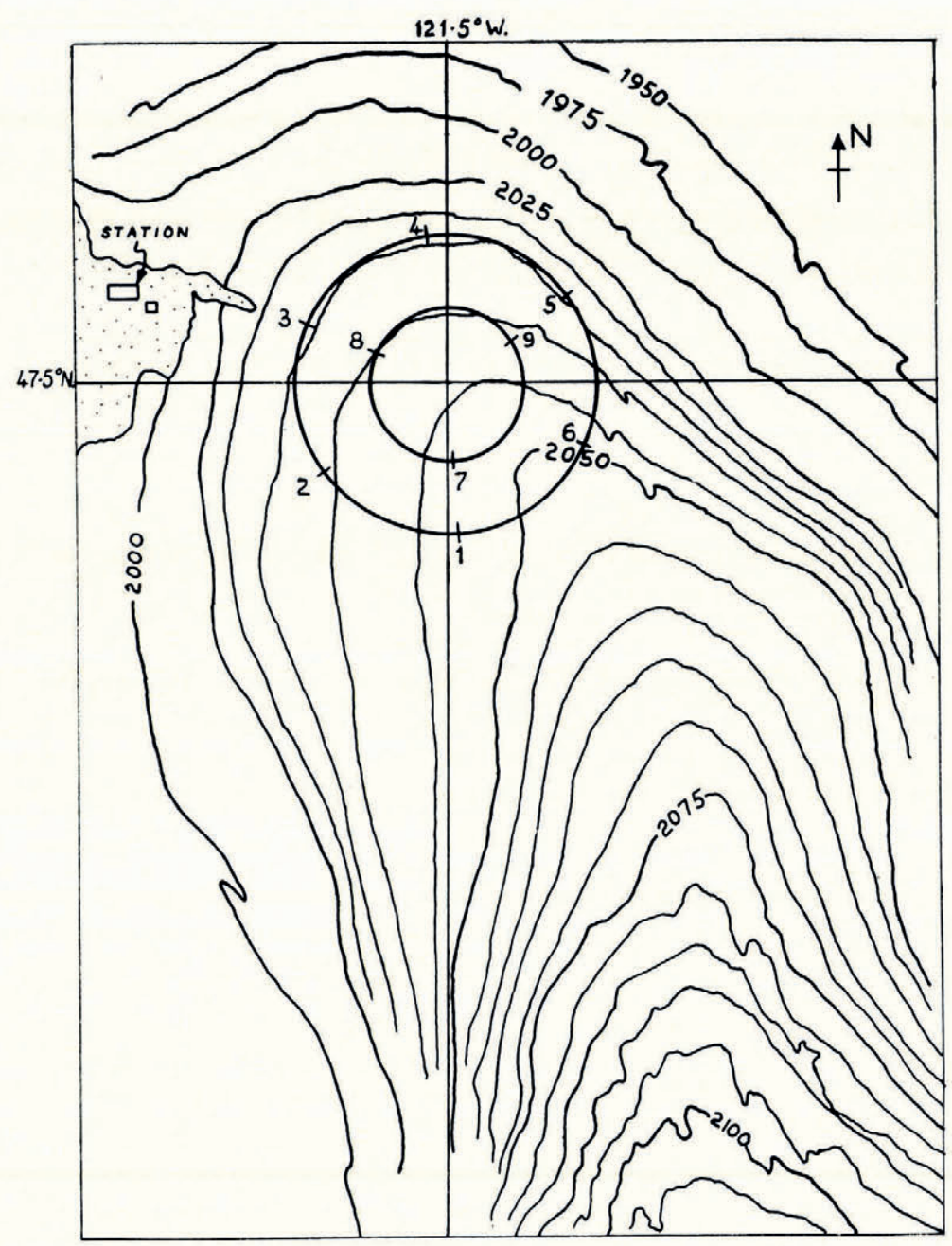

Fig. 1. Topography of the snow-dome and location of the Blue Glacier Field Station. The circles on the snow-dome indicate the areas of divergence measurements. Scale $1: 8,000$. Contour heights in meters

drainage down the side slopes and may be considered the first stage in the development of drainage. The air that is being cooled at the snow surface and consequently flows downhill must be replaced from above, therefore the average vertical velocity over the center is directly related to the horizontal divergence. If we consider an observation circle with radius $R$ (using the first technique) and assume that each anemometer is representative for the velocity over $\frac{1}{6}$ th the circumference of the circle, then the mass of air that leaves the circle in excess of the mass that enters, up to a height $h$, is given by

$$
m=\frac{2 \pi R \rho}{6} \sum_{n=1}^{6} \int_{0}^{h} \frac{\mathbf{V}_{z} \cdot \mathbf{R}}{R} d z
$$


where $\rho$ is the density of air, $\mathbf{V}_{z}$ is the horizontal velocity at height $z$, and $n$ is the number of the anemometer position. This outflow is due to subsidence of air from above. The mean vertical velocity $\bar{w}$ over the area of the circle at the height $h$ is therefore given by

or, combining with (I),

$$
\bar{w}_{h}=\frac{-m}{\rho \pi R^{2}},
$$

$$
\bar{w}_{h}=\frac{\mathrm{I}}{3 R^{2}} \sum_{n=\mathrm{I}}^{6} \int_{0}^{h} \mathbf{V}_{z} \cdot \mathbf{R} d z
$$

In order to evaluate the right hand side of equation (2) it is necessary to know the vertical profile of $\mathbf{V}_{z}$ from the surface to height $h$ along the circumference of the circle. The six anemometers were placed at $50 \mathrm{~cm}$. height along the circumference of the circle, therefore rather incomplete profiles were obtained. If it is assumed that the observations at $50 \mathrm{~cm}$. represent the average windspeed to a height of $100 \mathrm{~cm}$., equation (2) may be evaluated immediately. A somewhat better, although still fairly arbitrary, assumption is a logarithmic wind profile

$$
V_{z}=\frac{u_{*}}{k} \ln \frac{z+z_{0}}{z_{0}}
$$

where $u_{*}$ is the friction velocity, $k$ von Karman's constant, and $z_{0}$ the roughness length. For melting snow with suncups $z_{0} \simeq 0.5 \mathrm{~cm}$.

Substitution of this equation into equation (2) yields after integration

$$
\bar{w}_{h}=\frac{\mathrm{I}}{3^{2} \ln \left\{\left(5^{0}+z_{0}\right) / z_{0}\right\}}\left\{h \ln \frac{h}{z_{0}}-h+z_{0}\right\} \sum_{n=1}^{6}\left(\mathbf{V}_{50} \cdot \mathbf{R}\right)_{n} .
$$

The vertical velocities obtained with this equation are about 8 per cent smaller than with the first assumption when integrated over $100 \mathrm{~cm}$. height. The logarithmic profile assumption still tends to overestimate the actual value of $\bar{w}$ because the drainage wind profile shows a maximum usually below $100 \mathrm{~cm}$. It is conceivable therefore that the results presented in Table I are as much as 20 to 50 per cent too large when equation (4) is used.

Table I reveals that favorable conditions for the formation of drainage wind are a clear sky and warm air persisting for a few hours over the snow-dome. run 2.

As an illustration of a typical run, Table II gives the radial component of the wind for

It is apparent from this observation that very close to its origin the drainage wind is already at least as large as the prevailing wind.

Vertical downward velocities of air masses on the snow-dome were found to be of the order of $\mathrm{I} \mathrm{cm}$. sec. ${ }^{-1}$ at a height of $\mathrm{I} \mathrm{m}$. above the snow surface under fair weather conditions with no prevailing wind. When there was prevailing wind from a different direction than the drainage wind the divergence appeared to be rather weak and consequently low vertical velocities were obtained.

From an error analysis of divergence results, it was found that there was a possible error of $4^{\circ}$ per cent in the vertical velocities obtained by this technique. It is certainly desirable to have better accuracy of observations, but this requires a much more sophisticated instrumentation. It is gratifying, however, that the order of magnitude of the vertical wind relatively close to the surface has been obtained this way. 
The analysis for the second technique may be carried out in a similar way to the one described above; the results obtained with this method are also presented in Table I. However, the accuracy is even less than that of the first technique.

Table I. The Data and Results of Divergence Runs

\begin{tabular}{|c|c|c|c|c|c|c|c|}
\hline Run & Technique & Date & Time & Weather & $\begin{array}{l}\text { Height of } \\
\text { anemometers } \\
\mathrm{cm} .\end{array}$ & $\begin{array}{l}\text { Height of the } \\
\text { drainage wind layer }\end{array}$ & $\begin{array}{l}\text { Vertical } \\
\text { velocity } \\
\text { at } 1 \mathrm{~m} \text {. height } \\
\mathrm{cm} . \mathrm{sec}^{-\mathrm{I}}\end{array}$ \\
\hline $\mathrm{I}$ & Full circle & $\begin{array}{l}30 \text { July } \\
1963\end{array}$ & 18.45 & $\begin{array}{l}\text { St. cm. in valleys and } \\
\text { occasional fog. Pre- } \\
\text { vailing wind of } \mathrm{I}-3 \\
\text { knots from E. and } \\
\text { S.E. }\end{array}$ & 50 & $\begin{array}{l}\text { No clear demarcation; } \\
\text { the tempera ture } \\
\text { profile showing near } \\
\text { isothermal condi- } \\
\text { tions at the center }\end{array}$ & -0.21 \\
\hline 2 & Full circle & $\begin{array}{l}3 \text { August } \\
1963\end{array}$ & I 1.00 & $\begin{array}{l}\text { I/ io cloudy patches to } \\
\text { N. and S.W.; clear } \\
\text { overhead, no pre- } \\
\text { vailing wind }\end{array}$ & $5^{\circ}$ & $\begin{array}{l}\text { Transition zone at } \\
\text { about one meter }\end{array}$ & $-0 \cdot 9^{1}$ \\
\hline 3 & Full circle & $\begin{array}{l}3 \text { August } \\
1963\end{array}$ & II.30 & $\begin{array}{l}\text { I/ o cloudy patches in } \\
\text { the horizon; clear } \\
\text { overhead, no pre- } \\
\text { vailing wind }\end{array}$ & 50 & $\begin{array}{l}\text { Transition zone at } \\
\text { about one meter }\end{array}$ & $-0 \cdot 66$ \\
\hline 4 & Full circle & $\begin{array}{l}3 \text { August } \\
1963\end{array}$ & 12.00 & $\begin{array}{l}\text { Clear overhead; no } \\
\text { prevailing wind }\end{array}$ & $5^{\circ}$ & $\begin{array}{l}\text { Transition zone less } \\
\text { than one meter }\end{array}$ & $-1 \cdot 10$ \\
\hline 5 & $\begin{array}{l}\text { Concentric } \\
\text { circles }\end{array}$ & $\begin{array}{l}3 \text { August } \\
1963\end{array}$ & 12.30 & $\begin{array}{l}\text { Clear overhead; light } \\
\text { prevailing wind of } \\
2-3 \text { knots from S.W. }\end{array}$ & t & $\begin{array}{l}\text { Clear demarcation at } \\
\text { about } 50 \mathrm{~cm} \text {. }\end{array}$ & $-0 \cdot 9^{2}$ \\
\hline 6 & $\begin{array}{l}\text { Concentric } \\
\text { circles }\end{array}$ & $\begin{array}{l}3 \text { August } \\
1963\end{array}$ & 13.00 & $\begin{array}{l}\text { Clear overhead; light } \\
\text { prevailing wind of } \\
2-3 \text { knots from S.W. }\end{array}$ & $\begin{array}{l}\mathrm{t} \\
\mathrm{f}\end{array}$ & $\begin{array}{l}\text { Clear demarcation at } \\
50 \mathrm{~cm} \text {. }\end{array}$ & $-\mathrm{I} \cdot 06$ \\
\hline 7 & $\begin{array}{l}\text { Concentric } \\
\text { circles }\end{array}$ & $\begin{array}{l}3 \text { August } \\
\text { 1963 }\end{array}$ & $21 \cdot 30$ & $\begin{array}{l}\text { Clear overhead; no } \\
\text { prevailing wind }\end{array}$ & 50 & No clear demarcation & $-1 \cdot 00$ \\
\hline 8 & $\begin{array}{l}\text { Concentric } \\
\text { circles }\end{array}$ & $\begin{array}{l}3 \text { August } \\
1963\end{array}$ & 22.00 & $\begin{array}{l}\text { Clear overhead; no } \\
\text { prevailing wind }\end{array}$ & 50 & No clear demarcation & $-1 \cdot 19$ \\
\hline
\end{tabular}

Table II. Results of A Typical Run

\begin{tabular}{lcccccc}
\hline Anemometer position & $\mathrm{I}$ & 2 & 3 & 4 & 5 & 6 \\
Radial wind component $\mathrm{cm} . \mathrm{sec}^{-1}$ & -50 & +50 & +70 & $+\mathrm{I} 30$ & +100 & +80 \\
\hline
\end{tabular}

\section{Temperature Profiles over the Snow-dome}

There is a close relationship between the divergence of the flow with its resulting drainage wind and the vertical temperature profile over the snow surface, because the buoyant force of the cold air close to the surface is basically the cause of the drainage. A typical temperature profile observed during run 5 on 3 August 1963 near the center of the snow-dome under calm conditions is plotted in Figure 2. The cooling of the air by the snow surface affects the temperature up to a height of about $1 \mathrm{~m}$. Above this height the temperature is almost independent of height.

An attempt has been made to describe such a temperature profile theoretically. The area of observation on the snow-dome may be approximated by a cylinder with a radius of about $2,000 \mathrm{~m}$. Near the top of the snow-dome an average steady-state two-dimensional flow 




Fig. 2. Profiles of temperature, vertical velocity and coefficient

$$
a \equiv\left(\frac{g}{r} \frac{\Delta \theta}{\theta}\right)^{\frac{1}{2}}
$$

perpendicular to the cylinder (Fig. 3), may be described by the following equations for momentum, energy, and continuity:

$$
\begin{gathered}
\frac{\partial}{\partial x} \overline{\rho u^{2}}+\frac{\partial}{\partial z} \overline{\rho u w} \equiv \bar{\rho} g \frac{\Delta \theta}{\theta} \sin \phi, \\
\frac{\partial}{\partial x} \overline{\rho u \theta}+\frac{\partial}{\partial z} \overline{\rho w \theta}=0, \\
\frac{\partial}{\partial x} \overline{\rho u}+\frac{\partial}{\partial z} \overline{\rho w}=0 .
\end{gathered}
$$

Terms due to the curvature of the snow-dome are omitted because they are small.

The term on the right hand side of equation (5) is the buoyancy force: $\theta$ is the potential temperature, $\Delta \theta$ is the potential-temperature difference between the drainage-wind air close to the surface and the environmental air above at least $\mathrm{I} \mathrm{m}$. height, and $\phi$ is the elevation angle of the snow surface (Fig. 3). Near the center of the snow-dome $\sin \phi \simeq x / r$, where $x$ is the distance from the center of the snow-dome and $r$ is its radius of curvature. Since $\bar{u}=0$ 
for $x=0, \partial \bar{u} / \partial z \ll \partial \bar{u} / \partial x$ for small $x$ and equation (5) may be written after expanding and using equation (7) as

$$
\overline{\rho u} \frac{\partial \bar{u}}{\partial x}+\frac{\partial}{\partial x}\left(\bar{\rho} \overline{u^{\prime 2}}+\bar{u} \overline{\rho^{\prime} u^{\prime}}\right)+\frac{\partial}{\partial z}\left(\bar{\rho} \overline{u^{\prime} w^{\prime}}+\bar{w} \overline{\rho^{\prime} u^{\prime}}\right)=\frac{\bar{\rho} g x \Delta \theta}{r \theta} .
$$

Under calm conditions the turbulence is not strongly developed and horizontal and vertical variations in the turbulent fluxes of momentum are probably negligible in comparison to the change in the mean horizontal momentum flux. Therefore in the left-hand side of equation (8) the first term is the only significant one, and this equation reduces to

$$
\bar{\rho} \bar{u} \frac{\partial \bar{u}}{\partial x}=\bar{\rho} a^{2} x
$$

where $a^{2} \equiv \frac{g \Delta \theta}{r \theta}$. Since $\Delta \theta$ varies slowly in the horizontal but rapidly in the vertical, $a$ may be considered constant in the $x$ direction, but a function of $z$. Equation (9) may then be integrated to

$$
\bar{u}=a x
$$

because $\bar{u}=\mathrm{o}$ for $x=0$.

From equation (6) and the fact that pressure fluctuations are negligible in comparison to temperature and density fluctuations, i.e. $\rho^{\prime}\left|\bar{\rho}=-\theta^{\prime}\right| \bar{\theta}$, it follows that $\partial \bar{u} / \partial x+\partial \bar{w} / \partial z=0$. And combining this with equation (Io) yields

$$
\bar{w}=-\int_{0}^{z} a d z
$$

because $\bar{w}=0$ for $z=0$.

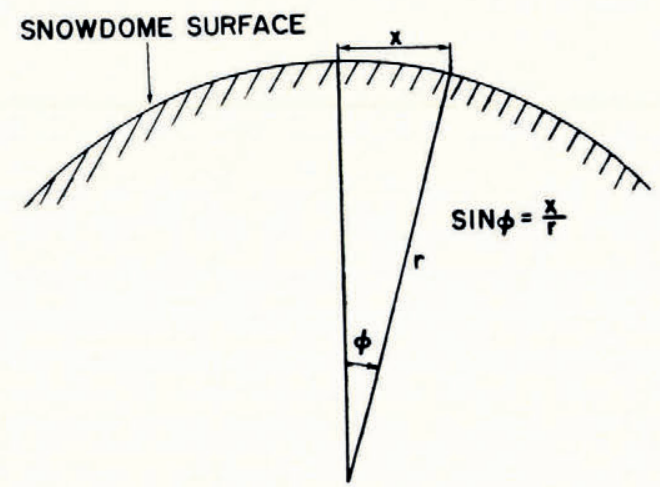

Fig. 3. Pseudo-Cartesian coordinates used near the top of the snow-dome

When the temperature profile is measured, it is possible to use equation (I I) to derive the vertical wind component independently from the divergence measurements. For this purpose the temperature profile plotted in Figure 2 was used. The derived profiles of $a$ and $\bar{w}$ have

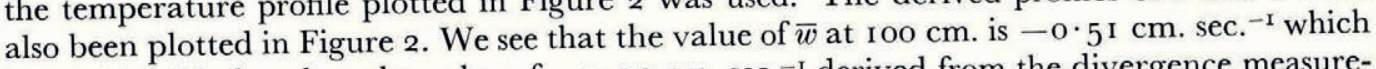
is considerably less than the value of $-0 \cdot 9^{2} \mathrm{~cm}$. sec. ${ }^{-1}$ derived from the divergence measure- 
ment. This difference may be partly caused by the inaccuracy of the divergence method and the fact that this method used tends to give us an overestimation of $\bar{w}$. However, it is also felt that the simple cylinder approximation of the snow-dome tends to give an underestimation of $\bar{w}$, because the actual shape is somewhere between cylindrical and spherical. For a spherical surface with the same radius of curvature the value of $\bar{w}$ would have been increased by about 40 per cent. For the discussion that follows the profiles of $\bar{w}$ and $a$ have been adjusted so that $\bar{w}_{100}=-0.92 \mathrm{~cm} . \mathrm{sec}^{-1}$, corresponding to the value obtained by the divergence measurement. These curves have also been plotted in Figure 2.

Finally equation (7) may be expanded in a similar way to (5) and (6), using again the relations $\rho^{\prime}\left|\bar{\rho}=-\theta^{\prime}\right| \bar{\theta}$, etc., with the result

$$
\bar{u} \frac{\partial \bar{\theta}}{\partial x}+\bar{w} \frac{\partial \bar{\theta}}{\partial z}+\frac{\partial}{\partial x} \overline{u^{\prime} \theta^{\prime}}+\frac{\partial}{\partial z} \overline{w^{\prime} \theta^{\prime}}=0 .
$$

Here we may assume that $\partial \bar{\theta} / \partial x \ll \partial \bar{\theta} / \partial z$ and that $\partial \overline{u^{\prime} \theta^{\prime}} / \partial x \ll \partial \overline{w^{\prime} \theta^{\prime}} / \partial z$, thus

$$
\bar{w} \frac{\partial \bar{\theta}}{\partial z}+\frac{\partial}{\partial z} \overline{w^{\prime} \theta^{\prime}}=0
$$

If we now assume that $\overline{w^{\prime} \theta^{\prime}}=-K_{H} \partial \bar{\theta} / \partial z$, where $K_{H}$ is the eddy thermal diffusivity and substitute equation (II) into equation (I $)$ the latter equation may be integrated to

$$
\bar{\theta}-\theta_{0}=\left\{\frac{\partial \bar{\theta}}{\partial z}\right\}_{0} \int_{0}^{z} \exp \left[-\int_{0}^{z^{\prime}} f d z^{\prime \prime}\right] d z^{\prime}
$$

where $f \equiv \frac{\mathrm{I}}{K_{H}}\left[\frac{\partial K_{H}}{\partial z}+\int_{0}^{z} a d z\right]$ and the index o refers to the surface of the snow.

The function $f$ depends on what assumption we make for $K_{H}$. It seems reasonable to assume that in the undisturbed air $K_{H}$ is constant, independent of height. This reflects a remnant of turbulence which is still present in the free air. When the air is brought close to the surface the vertical wind component is gradually suppressed and $K_{H}$ may be assumed to be a function of $z$.

Equation (13) has been worked out for two cases. In the first case it is assumed that $K_{H}$ is a linear function of $z$, i.e.

$$
\kappa_{H}=k u_{*}\left(z+z_{0}\right),
$$

and in the second case that $K_{H}$ is an exponential function of $z$, i.e.

$$
K_{H}=K_{\infty}\left[\mathrm{I}-\exp \left\{\frac{-k u_{*}}{K_{\infty}}\left(z+z_{0}\right)\right\}\right]
$$

where $K_{\infty}$ is a consequence of the remnant of turbulence present in the free air. A series of curves approximately agreeing with the observed one are possible with values of $u_{*}$ ranging from 2.0 to $4.0 \mathrm{~cm}$. sec. ${ }^{-1}$ in both cases and $K_{\infty}$ ranging from 500 to $5,000 \mathrm{~cm} .^{2} \mathrm{sec}^{-1}$ in the latter case. The best-fitting curve is shown in Figure 2.

Although equation ( 15 ) may appear more attractive from an intuitive point of view, the introduction of $K_{\infty}$ is an extra unknown parameter which allows for a wider range of arbitrary 
guesses. Since assumption (I4) leads also to a good description of the observed temperature profile it is preferable because of its simplicity. The good agreement between the measured and computed temperature profiles indicate that the theory is consistent with observations.

It should be emphasized that the theoretical arguments given here are only valid near the center of the snow-dome. As soon as the drainage wind itself has obtained sufficient strength, friction with the surface becomes significant and $\bar{\rho} \overline{u^{\prime} w^{\prime}}$ in equation (8) may no longer be neglected. Also entrainment of air from above may play a significant role in the momentum distribution. This extension requires further study both experimental and theoretical. A related study has been carried out by Ellison and Turner (1959).

\section{Estimation of the Turbulent Heat Flux into the Snow}

The enthalpy flux density at heights $h$ where the temperature is independent of height may be expressed by

$$
F_{H}(h)=c_{p} \rho(\bar{w} \bar{\theta})_{h} T / \bar{\theta}
$$

because here $\left(\overline{w^{\prime}} \overline{\theta^{\prime}}\right)_{h} \ll(\bar{w} \bar{\theta})_{h}$.

The coefficient $T / \bar{\theta}$ is a correction factor which is only significant if the observations are taken at high elevations. It decreases about 3 per cent per $\mathrm{r}, 000 \mathrm{~m}$. and in our case its value is 0.94 . Close to the surface $\bar{w}$ approaches 0 and the temperature fluctuations are large, therefore the enthalpy flux is then given by

$$
F_{H}(\mathrm{o})=c_{p} \rho\left(\overline{w^{\prime}} \overline{\theta^{\prime}}\right) \mathrm{o} T \bar{\theta}
$$

This last flux is not easy to measure directly but may be derived indirectly if we assume that in a column of air from the surface to about one meter a steady state exists. Then after combining with (I6)

$$
F_{H}(\mathrm{o})=\frac{c_{p} \rho T}{\bar{\theta}}\left\{(\bar{w} \bar{\theta})_{h}-\int_{0}^{h} a \bar{\theta} d z\right\}
$$

where the second term on the right-hand side expresses the enthalpy flux through the sides of the column as a result of horizontal divergence. We have assumed here that the divergence of horizontal turbulent heat flux is negligible. Since $\bar{w}, a$ and $\bar{\theta}$ are known the right-hand side of ( 18 ) can be evaluated.

On substituting the observational data, $F_{H}(0)$ is found to be $6 \cdot 05 \times 1 \mathrm{IO}^{-4} \mathrm{cal} . \mathrm{cm} .^{-2} \mathrm{sec}^{-1}$

by evaluating the integral in (I8) numerically.
$F_{H}(\mathrm{o})$ may also be estimated from the theoretical temperature profile (equation (I3)) which fits the observations best. Using $u_{*}=2 \cdot 8 \mathrm{~cm}$. sec. ${ }^{-1}, z_{0}=0.5 \mathrm{~cm}$. we find $\kappa_{H}(\mathrm{o})=$ $0.56 \mathrm{~cm}^{2} \mathrm{sec}^{-1}$, and from equation (13) we find $\frac{T \partial \bar{\theta}}{\bar{\theta} \partial z_{0}}=4 \cdot 18^{\circ} \mathrm{C} . \mathrm{cm} .^{-1}$. Therefore $F_{H}(\mathrm{o})=-c_{p} \rho K_{H}(\mathrm{o}) \frac{T \partial \tilde{\theta}}{\bar{\theta} \partial z_{0}}$ is found to be $-5 \cdot 7 \times 10^{-4}$ cal. $\mathrm{cm} .^{-2} \mathrm{sec}^{-1}$.

The agreement between the two methods only indicates that the equations used are consistent with each other, but does not reflect the accuracy of the result. The probable error is estimated to be \pm 30 per cent which is a consequence of the uncertainty in the determination of the vertical velocity component. 
When it is possible to improve the accuracy of the divergence measurement, we have here potentially a good method to determine the sensible heat flux density. It may be useful to incorporate this method in mass-budget studies on the glacier.

\section{Conclusion}

Although the results reported here are modest, it is promising that the picture obtained so far is consistent with observation. More accurate observations are needed for a real test of the theoretical arguments put forward and an effort should be made to obtain an independent check on the sensible heat flux to the snow which is the most difficult term to measure in the energy budget of a glacier. It is also desirable to obtain instantaneous values of $u$ and $\theta$, so that the neglected terms in equation (8) may be measured. These terms are recognized to be small by intuitive reasoning which should be confirmed by direct measurement.

\section{Acknowledgements}

This study was supported by grants from the National Science Foundation to the University of Washington, under contracts NSF G-1927I, GP-57I, and U.S. Army DA-AMC-36-039-63-G-I ; and the field work was under the guidance of Mr. E. R. LaChapelle, Department of Atmospheric Sciences, University of Washington.

MS. received I September 1964 and in revised form 23 April $196_{5}$

\section{REFERENCE} Ellison, T. H., and Turner, J. S. 1959. Turbulent entrainment in stratified flows. Journal of Fluid Mechanics, Vol. 6 ,
Pt. 3, p. 423-48. 